\title{
Knowledge co-production in climate adaptation planning of archaeological sites
}

\author{
Sandra Fatorić ${ }^{1}$ (D) Erin Seekamp ${ }^{2}$ \\ Received: 26 February 2019 / Revised: 2 May 2019 / Accepted: 6 May 2019 / Published online: 15 May 2019 \\ (C) The Author(s) 2019
}

\begin{abstract}
Climate adaptation is a process for minimizing the risks of damage or loss to coastal archaeological sites. Yet, adaptation requires identifying and prioritizing among the diverse aspects of a site's significance, as not all sites can be simultaneously adapted due to financial and human capital constraints. Developing a measurement framework that can ascertain the relative significance between sites necessitates the collaboration of multiple perspectives, including experts who set policy and on-the-ground managers who must translate policy into practice while accounting for the management preferences of associated communities. This paper explores if a values-based process enables co-production of knowledge related to the significance of archeological sites. Specifically, this paper examines the influences of a workshop - conducted with diverse archaeological experts working for the U.S. National Park Service — on knowledge co-production and documents the extent of changes in experts' opinions using a prepost survey design. Findings suggest that the values-based approach applied during the workshop can have a positive impact on knowledge co-production among experts. Changes were found in experts' perceptions of the importance of various considerations influencing archaeological site prioritization, as well as of the extent to which uncertainties challenge archaeological preservation. This paper presents novel findings about the importance of knowledge co-production in relation to coastal archaeological site preservation and climate adaptation in the U.S. Prioritization considerations and challenges of various uncertainties assessed in this study can provide valuable insights for progress in climate change policy for cultural heritage both in the U.S and globally.
\end{abstract}

Keywords Climate change adaptation $\cdot$ Social learning $\cdot$ Prioritization $\cdot$ Uncertainties $\cdot$ Values-based approach

\section{Introduction}

Archaeological sites are a static and non-renewable type of cultural heritage, which provide valuable social, cultural and economic benefits for the communities. For example, archaeological sites can foster social cohesion and identity among communities, increase community resilience, enhance education and advance scientific knowledge (Appler and Rumbach 2016; Flatman 2009; Hollesen et al. 2018). Archeological sites can also enhance capacity for learning and transferring archaeological knowledge

Sandra Fatorić

s.fatoric@tudelft.nl

Erin Seekamp

elseekam@ncsu.edu

1 Faculty of Architecture and the Built Environment, Delft University of Technology, Julianalaan 134, 2628, BL Delft, The Netherlands

2 Department of Parks, Recreation and Tourism Management, North Carolina State University, Raleigh, NC, USA into current social contexts and experiences, such as mitigation and adaptation to climate change (Lafrenz Samuels 2016; McVey Erlandson 2012). Furthermore, archaeological sites are important drivers of local and national economies, as they can contribute to increased tourism flows and generate or stimulate the tourism employment sector (Graham 2002; Cullinane Thomas et al. 2018). Yet, climate change-related impactssuch as, sea level rise, accelerated coastal erosion and flooding, more frequent and intense storms and hurricanes, increasing temperatures and precipitation changes, more frequent wildfires, increasing desertification, increasing permafrost thaw and decay of organic material (e.g., Anderson et al. 2017; Aryee and Apoh 2018; Breen 2007; Daly 2016; Dawson 2013; Daire et al. 2012; Hollesen et al. 2018; Rowland and Ulm 2012; Westley et al. 2011) - when combined with ongoing geomorphological processes (Howard et al. 2008; Reeder-Myers 2015) or biogeomorphic impacts (e.g., invasive species; Hilton et al. 2018) have major implications for archaeological sites preservation.

Climate-related impacts have already been observed to alter and accelerate archaeological sites' vulnerability in many places 
around the world (e.g., Aryee and Apoh 2018; Dawson 2013; Hollesen et al. 2018; Rowland and Ulm 2012). In this study, vulnerability is defined as the probability (degree) of losing archaeological sites' historical significance due to climate variability or change (Fatorić and Seekamp 2017b). Vulnerability of an archaeological site is characterized by (a) its location that could be adversely affected by a climatic event (i.e., exposure), and (b) the degree to which its historical significance could be affected by that exposure (i.e., sensitivity) (Rockman et al. 2016). Therefore, to reduce vulnerability and minimize the risks of damage or loss to archaeological sites, climate adaptation planning and implementation are crucial processes.

Climate adaptation of archaeological sites is a newly emerging research and policy area (Fatorić and Seekamp 2017a; UNESCO 2008) that aims to reduce the damages or enhance the benefits associated with current or potential future climate change impacts through planned action (IPCC 2014). Within the context of archaeological site adaptation, Heathcote et al. (2017) described two types of climate adaptation strategies. The first is a set of low-risk actions that focus on improving protection from changing climate conditions that are already happening, such as increased capacity of drainage systems to ensure archaeological sites are protected from water inundation and saturation. The second type are higher risk actions, which require adjustment of practices or even changes to what archaeological management or historic preservation currently find acceptable, such as changes to archaeological sites in areas of high wildfire risk to increase their fire resiliency. Yet when planning for adaptation, a careful and clearly defensible (i.e., transparent) process is needed since adaptation strategies can not only enhance resilience of the archaeological sites, but poorly designed strategies can also cause adverse impacts - even irreversible damage - to the values and characteristics associated with a site's significance. Additionally, there is a critical need for climate adaptation process that occurs before climate change-related damage to or loss of archaeological sites are further observed (i.e., proactive adaptation; IPCC 2014).

Setting priorities in archaeological site preservation and adaptation is a major challenge, especially where climate change risks are high, multiple archaeological sites are located across the landscape, and financial resources are limited (Rockman et al. 2016). One of the first attempts to address this challenge in the United States is federally issued policy guidance (NPS 2014), which urges heritage managers to make decisions that "are directed to resources that are both significant and most at risk". However, while we agree with the intention of this policy memorandum, a more proactive response is required to identify and analyze which factors or considerations are important when decision-makers prioritize sites for preservation and adaptation interventions, especially in the case of archaeological sites that are already facing the degradation or loss.
To solve the challenge of climate adaptation prioritization, we emphasize the need for applying a collaborative approach among policy-makers, decision-makers and practitioners to co-produce knowledge. Such co-production contrasts the traditional approach to knowledge creation, which is developed by researchers and then transferred to decision-makers (Polk 2015). Co-production of knowledge is defined as an iterative and transdisciplinary process of bringing multiple actor's knowledge and expertise together to address a decision problem and build an integrated understanding of that problem (Armitage et al. 2011). In this sense, co-production can better highlight knowledge differences and similarities, embrace a diversity of knowledge cultures, and allow for an expanded understanding of the problem or issue, which a single context might not produce (Simon et al. 2018). Furthermore, it is used to explore how multiple actors' knowledge develop and shift through iterative processes, building respect and trusted relationships among actors, and exploring the ways in which production of knowledge can occur in a more equitable and democratic process (Cundill 2010; Moser 2010; Filipe et al. 2017; Puente-Rodríguez et al. 2016; Richards et al. 2018). Maasen and Lieven (2006) pointed out that encouraging multiple actors' participation in the production of knowledge can foster the accountability of science, including the quality of the usability of results and outcomes (Polk 2015). Consequently, this can influence changes to practices, behaviors and values, and changes to and support of evidence-based policy making process (Filipe et al. 2017; Rist et al. 2006).

Co-production of knowledge has been increasingly acknowledged in environmental management and, more recently, climate adaptation as an important issue to enable discourse, transparency, validate knowledge and shared stewardship of the environment or natural resources, including promotion of sustainable practices (e.g., Armitage et al. 2011; Frantzeskaki and Kabisch 2016; Lebel et al. 2010; Muro and Jeffrey 2008; Puente-Rodríguez et al. 2016). To date, however, only one study (Fatorić and Seekamp 2017b) illustrates how coproduction of knowledge among diverse practitioners, decision-makers, policy-makers and researchers occurs and serves as valuable approach to inform climate adaptation planning of cultural heritage (i.e., historic buildings). In this paper, we address this important gap and explore if the co-production of knowledge about the prioritization considerations for climate adaptation planning occurred during a workshop with experts from archaeological site preservation, management and policy in the U.S. By advancing the understanding of knowledge coproduction in climate adaptation and archaeological site context, we not only inform the evidence-based decision-making process, but also respond to Intergovernmental Panel on Climate Change (IPCC 2018) and U.N. Educational, Scientific and Cultural Organization (UNESCO 2008)'s call for capacity building, knowledge development and exchange among cultural heritage stakeholders. 


\section{Methods}

Findings presented in this paper are part of a larger project and only represent a part of the data collected during a valuesbased, deliberative workshop on climate adaptation planning of archaeological sites in the U.S. The specific goals of this paper were: to (1) assess the extent to which knowledge coproduction occurred during a deliberative and values-based workshop with an array of policy-makers, decision-makers, and practitioners about prioritization of archeological sites for climate adaptation, and (2) identify and discuss the most and least important climate adaptation prioritization criteria as perceived by the workshop participants.

A multidisciplinary project team of four female researchers (two from the North Carolina State University and two representatives of the National Park Service) organized and facilitated a two-day workshop that was held in Washington, DC in November 2018. The workshop participants (identified through purposive sampling) consisted of 17 experts from various National Park Service (NPS) programmatic offices who have diverse expertise in archaeological site preservation and management at local, Tribal, state and national scales, as well as in climate change, and NPS national policy and regulations. ${ }^{1}$ It is important to note that careful consideration was given to select a group of experts with diversity of professional backgrounds and expertise who work on the frontline of policy- and decision-making (various NPS programs and offices), rather than from a statistically representative sample of a broader archaeological experts in the U.S. (Bryman 2008) or broader definitions of knowledge co-production that focus on the participation of citizens, decision-makers and researchers to restore public trust in science (Bäckstrand 2004). The intention of this study was to achieve analytic generalization which can yield new data on unexplored issues of knowledge co-production in climate adaptation of archaeological sites (Polit and Beck 2010), rather than statistical generalization (i.e., expert sample need to be representative of the population). Moreover, our focus on select NPS experts is an important first step for the agency to address climate adaptation policy guidance (NPS 2014) given not only the complexities of climate change science but also the predominance of a preservationist paradigm (DeSilvey 2017) that is challenged by both measuring relative significance and accepting losses of archaeological resources.

Drawing on work conducted in the field of decision analysis and behavioral decision theory (Keeney 1992), a values-

\footnotetext{
${ }^{1}$ Experts were employed within the following NPS programs, offices, and parks: Archaeology Program, Climate Change Response Program, Cultural Anthropology Program, National Historic Landmarks Program, National Register of Historic Places Program, Vanishing Treasures Program, Northeast Region Archaeology Office, Alaska Region Archaeology Program, National Capital Regional Office, Southeast Regional Office, and Colonial National Historical Park.
}

based approach, similar to the one applied by Fatorić and Seekamp (2017b), was applied to explore a limited understanding on knowledge co-production in climate adaptation of archaeological sites. Value-based approaches place emphasis on the importance of integrating experts' values with technical and scientific information in more transparent, inclusive and holistic response to environmental challenges (e.g., Espinosa-Romero et al. 2011; Gregory et al. 2012; Moore and Runge 2012). In our study, the research team first developed a beta framework of attributes (i.e., indicators) for measuring archaeological site significance (the values of a site) and the sensitivity of archeological sites to climate change impacts. The beta framework was developed from the scientific literature and policy documents over a two-month period prior to the workshop. At the beginning of the workshop, the research team provided an overview of ongoing challenges facing archaeological site preservation from climate change - including technical information on climate change impacts and uncertainties, as well as policy guidance and limitations - and an overview of similar efforts to develop measurement frameworks for historic buildings (Fatorić and Seekamp 2018), and an overview of an ongoing process for coastal archaeological site adaptation at a National Historical Park. Then, the research team facilitated a discussion about the key values and adaptation considerations of coastal archaeological sites, followed by an overview of the beta framework and a discussion about their initial reactions to the beta framework. Next, the participants worked in multidisciplinary subgroups to revise framework, which continued into the second day of the workshop, and culminated in a group-led presentations and subsequent facilitated discussion of the revisions.

A part of the workshop goals, and those that are the focus of this paper, was to explore whether there were any changes in experts' opinions after the workshop, and the extent of such changes, using a pre-survey and postsurvey design. Pre-post survey research aimed to assess the extent to which a participatory workshop influenced opinions about coastal archaeological site adaptation. At the beginning of the workshop, experts were asked to complete a pre-survey before delivery of any information. At the completion of the workshop, all participants were asked to fill out the post-survey. Both surveys included the following 4 questions and corresponding themes: (1) influence of value-based process on their perceptions, (2) potential for co-production of knowledge, (3) importance of considerations in prioritizing archaeological site for climate adaptation planning, and (4) challenges related to the uncertainties in archaeological preservation and climate adaptation planning (see Table 1). Additionally, the post-survey included a question that sought the feedback on the workshop's utility. Experts' perceptions were measured on a five-point agreement Likert scales $(1=$ lowest score, and $5=$ highest 
Table 1 Influence of workshop in changing participants' opinions from pre-workshop survey to post-workshop survey $(n=10)$

Survey questionnaire items Pre-Workshop Post-Workshop Unchanged Increase in Decreasein Mean (SD) Mean (SD) strength strength

1. To what extent do you think this value-based process will/did influence your thoughts on archaeological site preservation process? ${ }^{\mathrm{a}}$

a) Extent that value-based process will/did influence the thoughts on ar- $3.2(0.42) \quad 3.8(0.92) \quad 40 \% \quad 50 \% \quad 10 \%$ chaeological site preservation

b) Extent that value-based process will/did influence the thoughts on ar- $3.9(0.57) \quad 4.1(0.88) \quad 60 \% \quad 30 \% \quad 10 \%$ chaeological site preservation under changing climate

2. To what extent do you think this workshop will demonstrate the potential for co-production of knowledge? ${ }^{\mathrm{b}}$

$$
3.2(0.67) \quad 3.8(0.79) \quad 56 \% \quad 44 \% \quad 0 \%
$$

3. How important are the following considerations in prioritizing archaeological site for climate adaptation planning and preservation on a 30-year time horizon? ${ }^{\mathrm{c}}$

a) A preservation treatment has been applied to the site

$3.4(0.84)$

$3.4(0.70)$

$4.5(0.71)$

$4.2(1.23)$

$3.1(0.88)$

$2.4(0.84)$

g) The site provides significant tourism revenue to local communities

h) The site is widely visited by the public

$2.5(0.97)$

i) The site has high scientific value (helps us better understand aspects of $4.4(0.84)$ our historic past

j) The site holds a particular historical value because it is the only one like it $4.4(0.70)$ (rare example)

k) The site illustrates something of national importance

1) The programmatic function of the site to a National Park unit (link to the 3.7 (1.16) foundational purpose of the park unit)

m) The interpretive function of the site to a National Park unit (link to the $3.2(1.14)$ interpretive plan of the park unit)

n) The vulnerability of the site to climate-change threats (severity of risk) $4.1(0.88)$

o) The immediacy of climate-change related impacts (urgency of action) $4.3(0.67)$

p) The vulnerability of the site due to deferred maintenance

$3.4(0.97)$

q) The vulnerability of the site due to insufficient funding

$3.1(1.10)$

4. How challenging are the following uncertainties in archaeological preservation and

a) Timing of changes in precipitation, sea level, hurricanes

$4.0(0.82)$

b) Magnitude of changes in precipitation, sea level, hurricanes

$4.0(0.94)$

c) Coastal planning \& management

$3.2(1.40)$

d) Predictability of budget

e) Federal political environment

f) State political environment

g) Decision-makers' values and priorities

h) Stakeholders' values and priorities

i) Changes in archaeological policy

g) Working with SHPOs to preserve or adapt sites

$4.1(0.88)$

$4.0(1.05)$

$3.0(0.82)$

$3.9(1.20)$

$3.6(0.97)$

$2.8(1.30)$

$2.6(0.84)$

k) Prioritizing unknown sites (those sites that haven't been surveyed yet)

$\begin{array}{llll}3.2(1.03) & 40 \% & 20 \% & 40 \% \\ 3.1(1.10) & 50 \% & 10 \% & 40 \% \\ 3.2(1.03) & 30 \% & 30 \% & 40 \% \\ 3.8(1.03) & 40 \% & 10 \% & 50 \% \\ 3.8(1.03) & 60 \% & 0 \% & 40 \% \\ 3.4(0.70) & 40 \% & 40 \% & 20 \% \\ 2.6(0.84) & 50 \% & 30 \% & 20 \% \\ 2.8(0.63) & 80 \% & 20 \% & 0 \% \\ 4.6(0.70) & 80 \% & 20 \% & 0 \% \\ 4.6(0.70) & 60 \% & 30 \% & 10 \% \\ 4.5(0.71) & 80 \% & 20 \% & 0 \% \\ 4.1(0.88) & 60 \% & 40 \% & 0 \% \\ 3.3(0.82) & 30 \% & 40 \% & 30 \% \\ 3.9(0.74) & 60 \% & 10 \% & 30 \% \\ 4.0(0.67) & 50 \% & 10 \% & 40 \% \\ 3.1(0.99) & 30 \% & 30 \% & 40 \% \\ 3.3(1.16) & 30 \% & 50 \% & 20 \%\end{array}$

adaptation planning? ${ }^{\mathrm{d}}$

$3.7(1.06) \quad 30 \%$

$10 \%$

$40 \%$

$3.4(1.17) \quad 30 \% \quad 50 \% \quad 20 \%$

$4.0(1.25) \quad 60 \% \quad 20 \% \quad 20 \%$

$4.0(1.15) \quad 70 \% \quad 10 \% \quad 20 \%$

$2.8(1.14) \quad 50 \% \quad 20 \% \quad 30 \%$

$4.1(0.99) \quad 50 \% \quad 30 \% \quad 20 \%$

$3.4(0.52) \quad 40 \% \quad 20 \% \quad 40 \%$

$2.7(0.67) \quad 45 \% \quad 22 \% \quad 33 \%$

$\begin{array}{llll}2.7(0.95) & 30 \% & 40 \% & 30 \%\end{array}$

$3.3(1.42) \quad 67 \% \quad 11 \% \quad 22 \%$

a Measured on a 5-point Likert-type scale from "No influence" to "Extremely influential"

${ }^{\mathrm{b}}$ Measured on a 5-point Likert-type scale from "No co-production" to "Complete co-production"

${ }^{\mathrm{c}}$ Measured on a 5-point Likert-type scale from "Not at all important" to "Extremely important"

${ }^{\mathrm{d}}$ Measured on a 5-point Likert-type scale from "Not at all challenging" to "Extremely challenging"

score). Each participant was provided with a set of surveys that were assigned a unique identification number to enable a matched pairs design. No demographic and background data were collected to enhance 
confidentiality of responses. All protocols and instruments were approved by the North Carolina State University Institutional Review Board.

Of 17 workshop participants, only 14 were eligible for the pre-post study as 3 experts participated in the workshop remotely. Of those 14,12 participants completed pre-surveys, while 10 participants completed post-surveys. Thus, 10 matching pre- and post-surveys were analyzed using the Microsoft Excel software to calculate means, standard deviations, and direction of change in responses: unchanged strength, increased strength, and decreased strength. Both surveys took about $10-15$ min to complete.

\section{Results}

The results of this study suggest that experts' opinions about various aspects of climate change and archaeological site intersection were different before and after the workshop for the majority of questionnaire items (58\%), as shown in Table 1. Moreover, for those experts who changed their perceptions about the influence of value-based processes on their thoughts about archaeological site preservation, generally and under a changing climate, and the potential for co-production of knowledge, a greater proportion increased (as opposed to decrease) the strength of their opinion ( $50 \%$ vs. $10 \%, 30 \%$ vs. $10 \%$, and $44 \%$ and $0 \%$, respectively). Specifically, experts perceived that the values-based approach applied during the workshop held a moderate to high level of influence on their opinions about archaeological site preservation in general (pre-survey $\overline{\mathrm{X}}=3.2$; post-survey $\overline{\mathrm{X}}=3.8$ ) and archaeological site preservation under changing climate (pre-survey $\overline{\mathrm{X}}=3.9$; post-survey $\overline{\mathrm{X}}=4.1$ ). Experts opined that participating in the workshop resulted in high levels of knowledge co-production (post-survey $\overline{\mathrm{X}}=3.8$ ), which increased from their expectations documented in the pre-survey $(\overline{\mathrm{X}}=3.2)$.

Some changes in experts' perceptions of the importance of various considerations influencing archaeological site prioritization were found (Table 1). At least $50 \%$ of experts did not change their opinions about the importance of ten of the seventeen $(59 \%)$ considerations, with $80 \%$ of experts not changing their opinions about the sight being open to the public (pre-surveys $\bar{X}=2.5$; post-surveys $\bar{X}=2.8$ ), sites with high scientific value (pre-surveys $\bar{X}=4.4$; post-surveys $\bar{X}=4.6$ ), and sites that illustrate national importance (pre-survey $\overline{\mathrm{X}}$ $=4.1$; post-survey $\overline{\mathrm{X}}=4.5$ ). The most important considerations for prioritizing archaeological sites for climate adaptation planning in both pre- and post-surveys included: sites with high scientific value and sites holding a particular uniqueness or rarity (both pre-surveys $\bar{X}=4.4$; post-surveys $\bar{X}=4.6$ ), sites that illustrate national importance (pre-survey $\bar{X}=4.1$; post- survey $\bar{X}=4.5$ ), and sites in which action is urgent due to the immediacy of climate change threats (pre-survey $\bar{X}=4.3$; post-survey $\bar{X}=4.0$ ). Additionally, the post-survey results reveal that sites hold a programmatic function was also an important prioritization consideration (post-survey $\overline{\mathrm{X}}=4.0$ ). The lowest rated prioritization considerations (slight to moderate importance) perceived by experts in both the pre- and postsurveys included: sites that provide significant tourism revenues for local communities (pre-survey $\overline{\mathrm{X}}=2.4$; post-survey $\overline{\mathrm{X}}$ $=2.6$ ) and sites that are widely visited by the public (pre-survey $\bar{X}=2.5$; post-survey $\bar{X}=2.8$ ).

For all but one of the considerations (sites that hold meaning for local communities), we found at least one expert increased the strength of perceived importance, ranging from $10 \%$ to $50 \%$ (Table 1). The considerations with the largest proportions of experts' strengthening their opinion on their importance included: a site's vulnerability due to insufficient funding (50\%), a site's central role in the cultural landscape (40\%), a site's programmatic function (40\%), and a site's interpretive function (40\%). For all but three considerations, we found at least one expert decreased the strength of perceived importance, ranging from $10 \%$ to $50 \%$. Sites that hold meaning for a group of individuals revealed the greatest decrease (50\%) among the considerations for archaeological site prioritization. Other considerations with large decreases in perceived importance (40\%) included: sites with prior preservation treatments (pre-survey $\overline{\mathrm{X}}=3.5$; post-survey $\overline{\mathrm{X}}=3.2$ ), costs of continuous treatment (pre-survey $\overline{\mathrm{X}}=3.4$; post-survey $\overline{\mathrm{X}}$ $=3.1$ ), future maintenance costs (pre-survey $\bar{X}=3.4$; postsurvey $\bar{X}=3.2$ ), sites that hold meaning for a local community (pre-survey $\bar{X}=4.2$; post-survey $\bar{X}=3.8$ ), sites in which action is urgent due to the immediacy of climate change threats (presurvey $\overline{\mathrm{X}}=4.3$; post-survey $\overline{\mathrm{X}}=4.0$ ), and sites that are vulnerable due to deferred maintenance (pre-survey $\overline{\mathrm{X}}=3.4$; postsurvey $\overline{\mathrm{X}}=3.1$ ).

Among the challenges related to the uncertainties in archaeological preservation and climate adaptation planning, we found that the greatest challenges reported at the beginning and end of the workshop included: the predictability of budgets (pre-survey $\bar{X}=4.1$; post-survey $\bar{X}=4.0$ ) and the federal political environment (pre-survey $\overline{\mathrm{X}}=4.0$; post-survey $\overline{\mathrm{X}}$ $=4.0$ ) (Table 1). These uncertainties, along with those affiliated with the timing of climate change impacts, state's political environments, the values and priorities of decision-makers, and the ability to prioritize unknown sites, were affiliated with at least half $(50 \%)$ of the experts not changing their opinion between the pre- and post-surveys. The least challenging uncertainties reported at the beginning and end of the workshop included: the state political environment (pre-survey $\overline{\mathrm{X}}=3.0$; post-survey $\bar{X}=2.8$ ), changes in archaeological policy (presurvey $\overline{\mathrm{X}}=2.8$; post-survey $\overline{\mathrm{X}}=2.7$ ), and working with State 
Historic Preservation Offices (SHPOs) to preserve or adapt sites (pre-survey $\bar{X}=2.6$; post-survey $\bar{X}=2.7$ ). Substantial (40\% of experts) decreases in the strength of several challenges were found: the timing and the magnitude of changes in precipitation, sea level and hurricanes, as well as uncertainty in stakeholders' values and priorities. Half of the experts $(50 \%)$ demonstrated increases in the strength of the challenges associated with uncertainties in coastal planning and management. Several experts also demonstrated increases in the strengths associated with uncertainties related to working with SHPOs to preserve or adapt sites (40\%) and decision-makers' values and priorities (30\%).

Lastly, experts were asked to rate the impact and usefulness of the workshop (Table 2). In general, experts agreed that the workshop was an engaging process to provide input about archaeological site prioritization under changing climate $(\overline{\mathrm{X}}$ $=4.4$ ), and also rated that it was a good way to provide input into decisions about archaeological sites $(\overline{\mathrm{X}}=4.2)$. Furthermore, experts agreed that values-based approach applied during the workshop helped them understand other's values and preferences for archaeological site prioritization under changing climate $(\bar{X}=4.1)$. Such a process was also perceived as a good strategy for the National Park Service to support archaeological site prioritization decisions $(\overline{\mathrm{X}}=4.1)$. Experts disagreed that the process was too complicated to understand $(\overline{\mathrm{X}}=2.3)$ and that was not enough information to make well-considered responses $(\overline{\mathrm{X}}=2.6)$.

\section{Discussion and conclusions}

Despite recognition that co-production of knowledge can have positive impacts on evidence-based decision-making in climate change and environmental management disciplines (Rist et al. 2006), co-production of knowledge to support cultural heritage management and preservation under changing climate conditions remains poorly understood. This paper fills this knowledge gap by demonstrating that it is possible to achieve knowledge co-production about archaeological site preservation and climate adaptation using a deliberative and values-based process. It should be noted that this study is based on a small and purposive expert sample and, as such, the results should be treated with caution; however, the novel insights reveal the importance of knowledge co-production in relation to coastal archaeological site preservation and climate adaptation. Specifically, the findings of this study suggest that the values-based approach applied during the workshop can have a positive impact on co-production of knowledge and social learning among experts. Furthermore, it is likely that this study itself contributed to the enhanced adaptive capacity of the 14 experts who participated in the workshop by increasing their awareness and understanding of valuesbased approaches, co-production of knowledge, importance of considerations in prioritizing archaeological sites for climate adaptation, and challenges in connection with various policy, management and data uncertainties.

Our results demonstrate that experts were interested in understanding in greater depth how their own and others' values and preferences influence archaeological site adaptation and preservation. Additionally, our findings suggest that the values-based process reduced the extent to which the experts felt challenged by many (nearly two-thirds) of uncertainties related to archaeological preservation and adaptation planning. These findings confirm some previous studies (e.g., Dietz 2013; Gregory et al. 2012), which have demonstrated that values-based approaches can improve the quality of decisions and enhance the capacity of the participants for future decision-making. As such, our study provides evidence of the need for deliberative discussions that raise awareness and knowledge co-production about the poorly understood intersection between archaeological site preservation and climate adaptation.

Table 2 Workshop participants' opinions about the workshop and value-based process $(n=10)$

Feedback on the workshop and value-based process: ${ }^{\text {a }}$

a) This is a good way to provide input into decisions about archaeological sites.

b) There was not enough information to make well-considered responses.

c) The process helped me to understand and express my values about archaeological site prioritization under changing climate.

d) The process helped me to understand and express my preferences for archaeological site prioritization under changing climate.

e) The process helped me to understand others' values about archaeological site prioritization under changing climate.

f) The process helped me to understand others' preferences for about archaeological site prioritization under changing climate.

g) The process was too complicated.

h) This workshop was an engaging process for providing input about archaeological site prioritization under changing climate.

i) This process is a good strategy for the National Park Service to make archaeological site prioritization decisions.

a Measured on a 5-point Likert-type scale from "Strongly disagree" to "Strongly agree" 
Several scholars (e.g., Appler and Rumbach 2016; Cassar and Pender 2005; Hambrecht and Rockman 2017; Hollesen et al. 2018; Sabbioni et al. 2010) highlighted that, in cultural heritage and climate change disciplines, knowledge production and improved knowledge sharing among diverse stakeholders, decision-makers and researchers are of utmost importance to respond efficiently to climate change challenges and to support evidence-based decision-making. Furthermore, co-producing and sharing knowledge and best practices, including the failures, can enhance adaptive capacity of decision-makers and increase resilience of archaeological sites to better adapt under changing climate (Pelling et al. 2008; Phillips 2014; Rockman et al. 2016). The process we outlined in this paper does not exclude or preclude specific actors but rather proposes that a variety of knowledge holders is essential for a successful knowledge co-production. Further research is needed to understand the values, preferences and knowledge of other stakeholders and community groups, as well as to explore the impact of values-based processes that involve multiple actors on coproduction of knowledge and social learning.

The growing urgency of identifying how to create transparent and robust climate adaptation prioritization process for coastal archaeological sites presents a great challenge to wide range of stakeholders and decision-makers globally (e.g., Heilen et al. 2018; Carmichael et al. 2018; Dawson 2013). Within this initial phase of identifying and understanding considerations that might guide prioritization of adaptation across multiple archaeological sites, our findings suggest that knowledge about diverse prioritization considerations was exchanged and co-produced during the workshop. Additionally, our findings suggest that sites' scientific value, uniqueness, spatial importance (i.e., national level sites), and programmatic function were perceived as the most important prioritization considerations.

Uniqueness has been found to be an important climate adaptation consideration within some NPS park units. For example, the Gateway National Recreation Area considered uniqueness, condition, and use potential as important characteristics of cultural heritage (including archaeological sites) in development of prioritization process (Rockman et al. 2016). Similarly, Heilen et al. (2018) suggested that site's uniqueness should be a critical component in the process of prioritizing vulnerable sites for preservation and adaptation interventions. Often times uniqueness and rarity are interchangeably used. For example, Manders et al.'s (2012) training manual for underwater archaeological site management in Asia and Pacific suggested that sites' uniqueness or rarity is one of the criteria for assessing historical significance of the archaeological sites. Likewise, Dawson (2013) developed a prioritization process for vulnerable coastal archaeological sites in Scotland that uses site rarity as one of the main criteria.

Regarding the site's scientific value, Australian International Council on Monuments and Sites (Australia
ICOMOS 2013) includes scientific value as one of the five values within cultural significance assessment processes. Similarly, Manders et al. (2012) uses scientific value as one criteria to determine the intrinsic values of underwater archaeological sites. There is, however, limited information about archaeological site's scientific value used in guiding decisions in the context of archaeological sites at risk from climate change beyond these documents.

In terms of sites' spatial importance, limited policy guidance and published literature discusses the relevancy of an archaeological site's significance at international, national or local scales. For example, the ShoreDIG project (Graham et al. 2017) developed in Scotland, focuses on assessment and monitoring of locally-valued coastal sites that are already vulnerable to climate-related impacts. A study conducted in Denmark (Lundhede et al. 2013) found that survey respondents were more willing to pay for preserving nationally and internationally unique archaeological sites than biodiversity in the same area, since biodiversity was perceived as easier to substitute than the archaeological sites (i.e., irreversible loss of archaeological sites). Interestingly, the experts participating in this study opined that community (both traditional and contemporary) engagement in decision-making process is crucial for more transparent and equitable preservation and adaptation of archaeological sites (i.e., local scale sites), but yet they rated a national level archaeological sites as being one of the most important consideration in prioritization process. This raises several questions that need further exploration in future research efforts. For example, can different groups of stakeholders (e.g., site managers, heritage practitioners and associated community members) agree on what aspects of archaeological sites are most important for guiding prioritization during climate adaptation planning processes? Additionally, how can we adapt archaeological sites considering a diversity of spatial levels and move beyond only focusing on nationally and internationally (e.g., World Heritage Sites) significant sites?

We also found that fiscal considerations - specifically, prior investments, ongoing investments, future investments, and vulnerability associated with deferred maintenance-were perceived to be among the least important considerations for prioritizing archeological sites for adaptation and associated with reduced importance by the end of the workshop. In particular, these results are interesting as the experts reported budget uncertainties to be one of the greatest challenges facing archaeological preservation and adaptation planning (and the strength of their opinions about the extent of this challenge remained relatively stable throughout the workshop). Anderson et al. (2017) pointed out that the costs of preservation efforts are important factor in decision-making process since the funding is often limited and require a substantial justification. Similarly, Cassar and Pender (2005) suggested that the acceptance of what cultural heritage is worth safeguarding for future generations depends of value, 
significance, and financial resources. Moreover, a study on barriers to cultural heritage preservation and adaptation (Fatorić and Seekamp 2017c) found that available funding is one of three most salient barriers for heritage preservation and adaptation in the U.S. Some scholars (e.g., Barr 2017; Heilen et al. 2018) also stressed that cost of comprehensive assessments and surveys of both known and unknown archaeological sites is an important aspect in preservation and adaptation. We agree with these previous works and argue that addressing costs of maintenance, preservation or adaptation strategies is a critical consideration, as relative management costs are equally important as benefits in budget allocation decision-making (Courtois et al. 2018). As such, more research is needed to better understand the various socio-cultural, economic, environmental and political considerations that actually influence on-the-ground prioritization of cultural heritage for climate adaptation, in general, and of archaeological sites, specifically. Yet, perhaps even more important is the need for studies that assess the acceptability of climate adaptation decisions when decision-makers' considerations for selecting priorities are made transparent to diverse stakeholder groups.

As shown in some previous studies (e.g., Armitage et al. 2011; Dietz 2013; Lebel et al. 2010), knowledge sharing and co-production, including the incorporation of lessons learned, can reduce uncertainties and improve proactive climate adaptation outcomes. As Huitema et al. (2016) argued, the presence of uncertainties and related knowledge gaps do not justify adaptation policy inaction, especially not in regard to irreplaceable and non-renewable archaeological sites. Prioritizing archaeological sites for preservation and adaptation is not a simple task under climate, economic and social uncertainties, but current archaeological site preservation decisions are typically set on the basis of available data (NPS 1983). We consider that "best-bet" approach, which uses available data, is better than ad-hoc decisions, which are often based on decision-maker's preferences, biases, or power dynamics. As such, there is a need to advance the understanding of various uncertainties in archaeological site preservation and climate adaptation.

In conclusion, previous studies suggest that co-production can reduce conflicts and foster empowerment and synergies among multiple actors in a deliberative process who can, in turn, perceive the resulting knowledge as credible and legitimate, and adopt such knowledge for decision-making (Lebel et al. 2010; Polk 2015). We found that during a deliberative and values-based workshop, experts developed the sense that their peers were transparent in information sharing, thus suggesting that credibility improved. Yet, additional work to integrate the values and knowledge of other extra-scientific actors (e.g., tribal elders and associated community groups) is needed to ensure more holistic climate adaptation planning of cultural heritage in the U.S., as well as in other developed and developing countries. Creating and sharing knowledge between researchers and multiple stakeholders (e.g., policymakers, decision-makers, practitioners, and associated communities) can form a more democratic basis for joint action in safeguarding archaeological sites against anthropogenic climate change. In the meantime, the set of prioritization considerations assessed in this study can provide valuable insights for cultural heritage and climate change policy-making in the U.S. and globally.

Acknowledgements Funding for this research was provided under Cooperative Agreement P13AC00443 between the United States Department of Interior, National Park Service and NC State University, Task Agreement Number P17AC00794: Assessing the Transferability of a Historic Resources Decision Support Model to Optimize Budget Allocation for Adaptation Planning. We would like to thank the experts who participated in this study for voluntarily sharing their opinions and time, as well as our colleagues at the National Park Service who helped identify the list of experts, as well as coordinate and facilitate the workshop: Dr. Marcy Rockman (former Climate Change Adaptation Coordinator for Cultural Resources) and Dr. Amanda Babson (Coastal Landscape Adaptation Coordinator, Northeast Region).

\section{Compliance with ethical standards}

\section{Conflict of interest None.}

Open Access This article is distributed under the terms of the Creative Commons Attribution 4.0 International License (http:// creativecommons.org/licenses/by/4.0/), which permits unrestricted use, distribution, and reproduction in any medium, provided you give appropriate credit to the original author(s) and the source, provide a link to the Creative Commons license, and indicate if changes were made.

\section{References}

Anderson DG, Bissett TG, Yerka SJ, Wells JJ, Kansa EC, Kansa SW, Noack Myers K, DeMuth RC, White DA (2017) Sea-level rise and archaeological site destruction: an example from the southeastern United States using DINAA (digital index of north American archaeology). PLoS One 12:e0188142

Appler D, Rumbach A (2016) Building community resilience through historic preservation. J Am Plan Assoc 82(2):92-103

Armitage D, Berkes F, Dale A, Kocho-Schellenberg E, Patton E (2011) Co-management and the co-production of knowledge: learning to adapt in Canada's Arctic. Glob Environ Chang 21:995-1004

Aryee VA, Apoh W (2018) Climate change and the mitigating tool of salvage archaeology: the case of the fort Kongensten site at Ada Foah. Ghana Legon Journal of the Humanities 29(2):81-115

Australia ICOMOS (2013) Understanding and assessing cultural significance. http://australia.icomos.org/wp-content/uploads/PracticeNote_Understanding-and-assessing-cultural-significance.pdf Accessed 12 January 2019

Bäckstrand K (2004) Civic science for sustainability: reframing the role of experts, policy-makers and citizens in environmental governance. Glob Environ Politics 3:24-41

Barr BW (2017) "An ounce of prevention is worth a pound of cure": adopting landscape-level precautionary approaches to preserve Arctic coastal heritage resources. Resources 6:18

Breen C (2007) Advocacy, international development and world heritage sites in sub-Saharan Africa. World Archaeol 39(3):355-370 
Bryman A (2008) Social research methods, $3^{\text {rd }}$ edn. Oxford University Press, New York

Carmichael B, Wilson G, Namarnyilk I, Nadji S, Brockwell S, Webb B, Hunter F, Bird D (2018) Local and indigenous management of climate change risks to archaeological sites. Mitig Adapt Strat Glob Chang 23(2):231-255

Cassar M, Pender T (2005) The impact of climate change on cultural heritage: evidence and response. In: Proceedings of the ICOM $14^{\text {th }}$ triennial meeting. The Hague. James \& James, London, pp 610-616

Courtois P, Figuieres C, Mulier C, Weill J (2018) A cost-benefit approach for prioritizing invasive species. Ecol Econ 146:607-620

Cullinane Thomas C, Koontz L, Cornachione E (2018) 2017 National park visitor spending effects: Economic contributions to local communities, states, and the nation, Natural Resource Report NPS/ NRSS/EQD/NRR-2018/1616. National Park Service, Fort Collins, $\mathrm{CO}$

Cundill G (2010) Monitoring social learning processes in adaptive comanagement: three case studies from South Africa. Ecol Soc 15(3): 28

Daire M-Y, Lopez-Romero E, Proust J-N, Regnauld H, Pian S, Shi B (2012) Coastal changes and cultural heritage (1): assessment of the vulnerability of the coastal heritage in Western France. J Isl Coast Archaeol 7(2):168-182

Daly C (2016) The design of a legacy indicator tool for measuring climate change related impacts on built heritage. Herit Sci 4:1-12

Dawson T (2013) Erosion and coastal archaeology: evaluating the threat and Prioritising action. In: HOMER conference proceedings BAR international series 2570. Archeopress, Oxford, pp 77-83

DeSilvey C (2017) Curated decay: Heritage beyond saving. University of Minnesota Press, Minneapolis MN

Dietz T (2013) Bringing values and deliberation to science communication. PNAS 110(3):14081-14087

Espinosa-Romero MJ, Chan KMA, McDaniels T, Dalmer DM (2011) Structuring decision-making for ecosystem-based management. Mar Policy 35(5):575-583

Fatorić S, Seekamp E (2017a) Are cultural heritage and resources threatened by climate change? A systematic literature review. Clim Chang 142(1):227-254

Fatorić S, Seekamp E (2017b) Evaluating a decision analytic approach to climate change adaptation of cultural resources along the Atlantic Coast of the United States. Land Use Policy 68:254-263

Fatorić S, Seekamp E (2017c) Securing the future of cultural heritage by identifying barriers to and strategizing solutions for preservation under changing climate conditions. Sustainability 9:2143

Fatorić S, Seekamp E (2018) Fatorić, S., \& Seekamp, E. (2018). A measurement framework to increase transparency in historic preservation decision-making under changing climate conditions. J Cult Herit 30:168-179

Filipe A, Renedo A, Marston C (2017) The co-production of what? Knowledge, values, and social relations in health care. PLOS Biol 15(5):e2001403

Flatman J (2009) A climate of fear: recent British policy and management of coastal heritage. Public Archaeol 8:3-19

Frantzeskaki N, Kabisch N (2016) Designing a knowledge co-production operating space for urban environmental governance-lessons from Rotterdam, Netherlands and Berlin, Germany. Environ Sci Pol 62: 90-98

Graham B (2002) Heritage as knowledge: capital or culture? Urban Stud 39:1003-1017

Graham E, Hambly J, Dawson T (2017) Scotland's eroding heritage: a collaborative response to the impact of climate change. Archaeol Rev Camb 32(2):141-158

Gregory R, Failing L, Harstone M, Long G, McDaniels T (2012) Structured decision making: a practical guide to environmental management choice. John Wiley \& Sons Inc, Hoboken, NJ
Hambrecht G, Rockman M (2017) International Approaches to climate change and cultural heritage. Am Antiq 82:627-641

Heathcote J, Fluck H, Wiggins M (2017) Predicting and adapting to climate change: challenges for the historic environment. Hist Environ Policy 8(2):89-100

Heilen M, Altschul JH, Lüth F (2018) Modelling resource values and climate change impacts to set preservation and research priorities. J Conserve Manage Archa 20(4):261-284

Hilton M, Walter R, Greig K, Konlechner T (2018) Burial, erosion, and transformation of archaeological landscapes: case studies from southern New Zealand (Aotearoa). Prog Phys Geogr 42(5):607-627

Hollesen J, Callanan M, Dawson T, Fenger-Nielsen R, Friesen TM, Jensen AM, Markham A, Martens VV, Pitulko VV, Rockman M (2018) Climate change and the deteriorating archaeological and environmental archives of the Arctic. Antiquity 92(363):573-586

Howard AJ, Challis K, Holden J, Kincey M, Passmore DG (2008) The impact of climate change on archaeological resources in Britain: a catchment scale assessment. Clim Chang 91:405-422

Huitema D, Adger WN, Berkhout F, Massey E, Mazmanian D, Munaretto S, Plummer R, Termeer CCJAM (2016) The governance of adaptation: choices, reasons, and effects, introduction to the special feature. Ecol Soc 21(3):37

Intergovernmental Panel on Climate Change (2014) IPCC fifth assessment report: climate change 2014, working group II: impacts, adaptation and vulnerability. Cambridge University Press, Cambridge, New York

Intergovernmental Panel on Climate Change (2018) Special report: global warming of $1.5^{\circ} \mathrm{C}$. https://www.ipcc.ch/sr15/ Accessed 16 December 2018

Keeney RL (1992) Value-focused thinking: a path to creative decision making. Harvard University Press, Cambridge

Lafrenz Samuels K (2016) The cadence of climate: heritage proxies and social change. J Soc Archaeol 16:142-163

Lebel L, Grothmann T, Siebenhüner B (2010) The role of social learning in adaptiveness: insights from water management. Int Environ Agreements 10:333-353

Lundhede T, Bille T, Hasler B (2013) Exploring preferences and non-use values for hidden archaeological artefacts: a case from Denmark. Int J Cult Policy 19(4):501-530

Maasen S, Lieven O (2006) Transdisciplinarity: a new mode of governing science? Sci Public Policy 33:399-410

Manders M, Van Tilburg H, Staniforth M (2012) Significance Assessment. In: Underwood MM. (ed) Training Manual for the UNESCO Foundation Course on the Protection and Management of Underwater Cultural Heritage in Asia and the Pacific. U.N. Educational, Scientific and Cultural Organization, Bangkok, pp Unit 6

McVey Erlandson J (2012) As the world warms: rising seas, coastal archaeology, and the erosion of maritime history. J Coast Conserv 16(2):137-142

Moore JL, Runge MC (2012) Combining structured decision making and value-of-information analyses to identify robust management strategies. Conserv Biol 26:810-820

Muro M, Jeffrey P (2008) A critical review of the theory and application of social learning in participatory natural resource management processes. J Environ Plan Manage 51(3):325-344

National Park Service (1983) Archeology and Historic Preservation: Secretary of the Interior's Standards and Guidelines. https://www. nps.gov/history/local-law/arch_stnds_0.htm Accessed 05 February 2019

National Park Service (2014) Policy Memorandum 14-02. https://www. nps.gov/policy/PolMemos/PM-14-02.htm Accessed 14 December 2018

Pelling M, High C, Dearing J, Smith D (2008) Shadow spaces for social learning: a relational understanding of adaptive capacity to climate change within organisations. Environ Plan A 40:867-884 
Phillips H (2014) Adaptation to climate change at UK world heritage sites: Progress and challenges. Hist Environ Policy 5:288-299

Polit DF, Beck CT (2010) Generalization in quantitative and qualitative research: myths and strategies. Int J Nurs Stud 47:1451-1458

Polk M (2015) Transdisciplinary co-production: designing and testing a transdisciplinary research framework for societal problem solving. Futures 65:110-122

Puente-Rodríguez D, Van Slobbe E, Al IAC, Lindenbergh DE (2016) Knowledge co-production in practice: enabling environmental management systems for ports through participatory research in the Dutch Wadden Sea. Environ Sci Pol 55:456-466

Reeder-Myers LA (2015) Cultural heritage at risk in the twenty-first century: a vulnerability assessment of coastal archaeological sites in the United States. J Isl Coast Archaeol 10(3):436-445

Richards J, Wang Y, Orr SA, Viles H (2018) Finding common ground between United Kingdom based and Chinese approaches to earthen heritage conservation. Sustainability 10:3086

Rist S, Chiddambaranathan M, Escobar C, Wiesmann U (2006) "It was hard to come to mutual understanding ..." - the multidimensionality of social learning processes concerned with sustainable natural resource use in India, Africa and Latin America. Syst Pract Act Res 19:219-237

Rockman M, Morgan M, Ziaja S, Hambrecht G, Meadow A (2016) Cultural resources climate change strategy. National Park Service, Washington, DC
Rowland MJ, Ulm S (2012) Key issues in the conservation of the Australian coastal archaeological record: natural and human impacts. J Coast Conserv 16(2):159-171

Sabbioni C, Brimblecombe P, Cassar M (2010) The atlas of climate change impact on European cultural heritage: scientific analysis and management strategies. In: Anthem press. London, New York

Simon D, Palmer H, Riise J, Smit W, Valencia S (2018) The challenges of the transdisciplinary co-production of knowledge: from unilocal to comparative research. Environ Urban 30(2):481-500

U.N. Educational, Scientific and Cultural Organization (2008) Policy document on the impacts of climate change on world heritage properties. UNESCO, Paris

Westley K, Bell T, Renouf MAP, Tarasov L (2011) Impact assessment of current and future sea level change on coastal archaeological resources - illustrated examples from northern Newfoundland. J Island Coast Archaeol 6(3):351-374

Publisher's note Springer Nature remains neutral with regard to jurisdictional claims in published maps and institutional affiliations. 